\title{
Support for Innovation Processes in Collaborative Networks
}

\author{
Heiko Duin ${ }^{1}$, Manuel Fradinho ${ }^{2}$, Marcus Seifert ${ }^{1}$, and Klaus-Dieter Thoben ${ }^{1}$ \\ ${ }^{1}$ BIBA - Bremer Institut für Produktion und Logistik GmbH, Hochschulring 20, \\ D-28359 Bremen, Germany \\ $\{d u$, sf, tho\} @biba.uni-bremen. de \\ ${ }^{2}$ Cyntelix Corporation Ltd., Dublin, Ireland
}

\begin{abstract}
Effective innovation is the key challenge for European manufacturing enterprises in the global market. New approaches such as Open Innovation combined with the Extended Product paradigm are currently heavily under discussion among practitioners as well as scientists. This paper provides a discussion of the processes and challenges in the early phase of innovation, i.e. the idea seeding, ideation and evaluation phases which take place before formally structured processes like stage-gate approaches are applied. Special attention is paid to learning and knowledge creation aspects. Additionally, aspects concerning further research directions are discussed.
\end{abstract}

Keywords: Innovation, Collaborative Innovation.

\section{Introduction}

In the global market, with the emergent economies, European enterprises have serious difficulties in surviving, let alone excelling, unless they are capable to leverage successfully their capacity to innovate. Enterprises in almost all sectors are forced to develop innovative products in shorter cycles due to market constraints. In this context, Wang and Ahmed [1] describe the market situation as dominated by hyperdynamics, uncertainty and chaos.

The innovation statistics carried out with European enterprises demonstrates a paradox in Europe of having good research activities, but with poor impact concerning innovation and global competitiveness [2]. The problem is not necessarily lack of funding, with the EU RTD program totaling 229 billion Euros in 2007, neither is it lack of engagement of enterprises in innovation (with exception of France), with $41.2 \%$ in industry and $36 \%$ in services [3]. However, the reality demonstrates that a total $85 \%$ of product development resources are wasted on products and services that never reach the market, which is compounded by the fact that only $18 \%$ of those products reaching the market actually prove successful [4,5]. In addition, the distribution of innovation across Europe is uneven, with Sweden, Finland, Germany, Denmark and the UK considered as innovation leaders in the European Innovation Scoreboard (EIS) in 2008 [2]. 
In response to the pressures resulting from competing in a global market, enterprises follow two major trends: Open Innovation and Extended Products.

\subsection{Open Innovation}

The limitations of the internally focused innovation are summarily captured in the simple simulation of Red Queen Effect [6] applied to product development. The simulation indicates that a $10 \%$ decrease in product life cycle would require a company to double the introduction of new sustainable products each year, which implies significant increases in innovation funding just to maintain for the company to keep its market position. This is a simple simulation based on shrinkage of the product lifecycle. If one considers the globalization phenomenon, then it is unthinkable to keep the closed innovation model. Consequently, organizations have been compelled to reach out beyond their boundaries to engage with others in the attempt of maximizing the efficiency of their innovation processes by collaborating with others. The realization that the world no longer allows for companies functioning in isolation has led to the establishment of a networked fabric composed of enterprises collaborating with one another based on a platform of trust - Collaborative Networked Organizations [7].

\subsection{Extended Products}

Facilitated by a paradigm of sustainable development in the vision of Adams [8], enterprises have realized that their customers are more interested in solutions to a need, rather than a packaged product. This introduces the concept of extended products, where a product is enriched with services and the business model is focused on what needs are addressed by the combined solution (e.g. [9]). So for example, one may consider that car manufacturers are moving away from providing a simple car towards providing a solution for mobility.

\subsection{Implications and Chances}

These trends have a significant impact on the way innovation has been traditionally viewed and dealt with by enterprises, which no longer consider it viable to harness alone the necessary creativity power within their corporate boundaries to excel. Consequently, the barriers of closed innovation have been torn down and the new paradigm of open innovation [10] has been adopted, where multiple parties are engaged thus increasing the creativity potential. Initially the paradigm of open innovation was applied solely to the enterprises, but the open innovation movement has gone even further than organizational boundaries reaching out towards individuals, realizing that the global connectivity provided by the Internet has created a Global Brain. This has led to the notions of crowd sourcing and the existence of a global brain, but there are multiple challenges towards harnessing successfully the power of the masses and the success cases are still more anecdotal rather than systematic.

A harsh reality concerning innovation is the low success rate of transforming ideas into sustainable business models, and in response, the Living Lab paradigm [11] has emerged where the creation process is not only open involving multiple innovators, 
but places the customer at the centre of the innovation process, actively taking part of the creation of products and services at every step. However, the novelty of Living Labs implies that there are serious challenges for individuals and organizations to adopt the paradigm to produce successful outcomes.

\section{Innovation}

Innovation in public is often seen as the invention of something groundbreaking new. Innovation isn't solely concerned with the generation of new ideas but also with making an economical effort out of them. Innovation encompasses the entire process from the generation of an idea - the invention or the combination of known objects to the penetration of the market with a economically successful implementation of the idea - as much for products as for processes or services [12].

The innovation process therefore represents all phases from idea generation to marketing and sales. The diagram in Fig. 1 reflects the innovation from seeding of the idea until the new product development, which then leads to the operations.

A new concept is introduced by Henry Chesbrough [10]: Open Innovation. The central idea of Open Innovation is that in a world consisting of widely distributed knowledge, organizations like enterprises cannot afford to rely entirely on their own research. Instead they should buy or license processes or inventions (e.g. patents) from other companies. In addition, internal inventions which are not used in business could be taken outside the enterprise (e.g. by licensing or joint ventures). On the other hand side collaboration in the critical phase of product innovation conducts the reduction of the in-house production depth and leads to the dependency of external partners.

Another solution or a concept enhancing the open innovation idea is the concept of European Living Labs. These offer a unique opportunity for organizations to include end-users and other stakeholders in new product development or other innovation processes. This enables the user to be a co-creator in the innovation process [11].

These approaches have the early stage of innovation in focus. The early stage of innovation is characterized by high uncertainties and the constant generation of new and relevant knowledge [13]. The knowledge is generated and immediately used in non linear work steps. The complexity of these work processes cannot be described appropriate in a quantifiable model [14]. This is taken into account as today's attempts do not have the pretence to describe the early stage processes in a whole within methods or best practice examples [15].

Within the early stage of innovation up to $70 \%$ of all follow up costs are determined [16]. Taken into account the high development cost in the automotive sector the understanding and the successful support of the early stage of innovation becomes indispensible for economical success.

\subsection{Ideation}

Ideation is a concept that is generally not understood well in depth. In many organizations ideation is viewed similar to creating ideas. However, creating ideas is only the very initial seed for the ideation process. Recent empirical studies have 


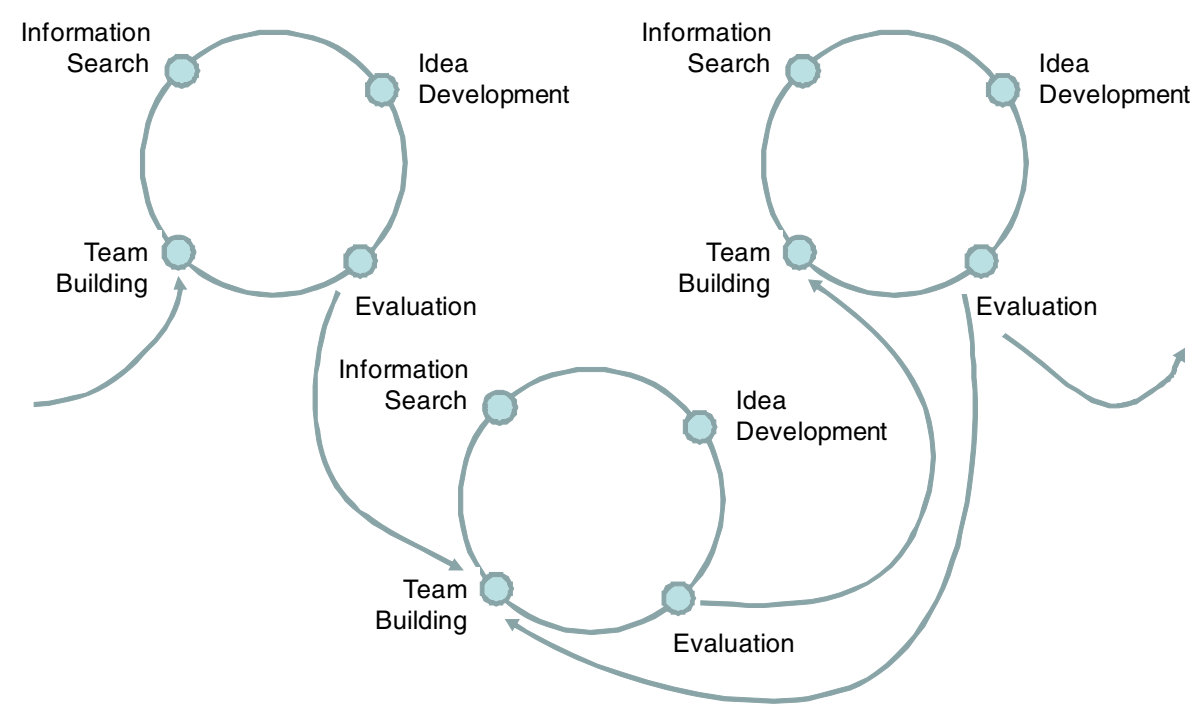

Fig. 2. Ideation process

revealed that the process of generating ideas is not considered as a problem in industrial organizations - the perceived problem is the continuing idea development process - the ideation process [17].

Ideation is basically a circular process (as shown in Fig. 2) that differs significantly from the sequential process approach that most people are trained in [18]. Furthermore, ideation is an inter-disciplinary and cross-organizational process that requires a certain degree of common language. Due to the inter-disciplinary nature the common language additionally has to be neutral [19].

Traditionally, problems have been seen as complicated challenges that should be solved through breaking them down into smaller and smaller chunks. However, most modern problems - and ideation problems in particular - are complex rather than complicated. Complex problems are messier and more ambiguous in nature; they are more connected to other and often very different problems; more likely to react in unpredictable non-linear ways; and more likely to produce unintended consequences.

The perception and response to complex issues are dependent on the nature of the sense-making process. The sense-making process, on the other hand, is dependent on the perceived nature of the problem.

\subsection{Connectivity}

The advent of Web 2.0 [20] concepts and technologies not only fostered users' active participation to content creation, and therefore transforming knowledge consumers into 'prosumers', but also boosted the collective creation of knowledge and made users keep active control on the kind of knowledge and information produced and diffused and on its quantity and quality too (e.g. Wikipedia). This new perspective [21] brought new life to innovation and, of course, to its creative component, as Web 
2.0 clearly supported the so called 'knowledge fusion' process that characterizes the knowledge creation emerging from combining, adapting and improving different knowledge components developed in different contexts as now commonly happens in diverse and dispersed professional environments.

McAfee [22] translated the Web 2.0 into the SLATES paradigm in order to bring it into the corporate (and more in general, organizational) environment by labeling it as ENTERPRISE 2.0. Therefore, by introducing ENTERPRISE 2.0-inspired tools in the work routine knowledge workers find in their organization the Web 2.0 social and collaborative tools they are already accustomed to. Moreover, in the Open Innovation perspective, the emergence of workers belonging to virtual communities not only within the organization itself, but also, extended beyond or, even completely external to it, can be not only tolerated, but even encouraged. A key point, as [23] pointed out, is related to the fact that in the cooperative creation process people like to ask for advice to, and receiving it from, their peers or the ones who are reputed being experts in some domains of knowledge. The explanation relies on the "emotional, psychological and social needs of individuals" that have to be fulfilled [24]. Therefore, it becomes apparent how sharing content and being part of virtual communities in blogs or in online video sharing websites or contributing to wiki projects and the use of any other Web 2.0 tool increase people feelings of self recognition, of reputation in the community, of being connected to other people which is one of the basic needs of individuals experience [25].

\subsection{Evaluation}

Evaluation is a general technique, which is applied in several domains, but in the particular domain of innovation, it has been mostly applied to product development where each process is completed by running evaluations against the objectives of the phase [26]. These objectives shift from phase to phase, for example form the completeness of requirements in the requirement phase, to feasibility in the design phase, or functioning in the implementation phase. In any case these evaluations are focused on technical criteria [27], which are categorized in groups of overall aims, such as manufacturability, assembly, ecology, maintenance, safety and others as design-for-X sets of constraints. Such evaluations are typically undertaken by test engineers in the development departments. It is recognized that such technical approach often leads to good but expensive solutions, which is overcome by adding a separate value analysis evaluation with cost/benefit measurements, often through a separate department and initially in a late design phase.

Evaluation draws on another source of quality management, risk management and project management, where the focus is more on identifying the potential impact of events on the development, production and delivery process. A well known example is the Fish-bone diagram [28], which relates possible product failures to its consequences, so that corrective actions can be taken already in the early design phases. Such evaluations are typically undertaken by dedicated risk / project / quality management departments following their own standard operation procedures.

A third evaluation perspective is a more recent, advanced-state-of-the-art financial and entrepreneurial perspective that is implemented in business idea competitions and business plan competitions [29]. Rather than an internal perspective on the product or 
the organization of its development, the focus of this evaluation is on its outside validity with questions like: will there be enough financial, personal and knowledge resources to complete the project? Will the result be acceptable to its users, and who are the users [30]? How likely is it that the idea under consideration will prevail over its contenders? Such evaluations are organizationally not yet well placed and are undertaken by associations and (ad hoc) board within the innovation ecosystem.

\section{Living Labs}

The initiative of Living Labs came up in the early nineties and the term Living Lab was firstly proposed by Lasher, Ives and Jarvenpaa [31] to the academic community. In Europe, Living labs gained more attention during the European test bed discussion from 2000 to 2004. Living Labs can be viewed as a method in the innovation process to integrate users. Simplified, Living Labs reverse the idea of product development to some extent. In this concept, consumers are involved in the innovation process from the inception of ideas thus they can directly influence the innovation process instead of being just customers of a pre-developed product.

Furthermore, a rather medium- and long-term time frame for conducted Living Lab studies is stated by common literature on Living Labs. In terms of the number of participants in Living Lab studies, there seems to be a slight change over the last years. Whereas at the beginning of Living Lab studies, the number of participants involved was rather small, nowadays the possibility of big user groups in Living Lab environments is rising [32].

As bottom line Folstad [33, p. 116] defines Living Labs as follows: "Living Labs are environments for innovation and development where users are exposed to new ICT solutions in (semi)realistic contexts, as part of medium- and long-term studies targeting evaluation of new ICT solutions and discovery of innovation opportunities".

\section{Conclusions and Research Directions}

The key challenge with innovation is to understand that it is more than the acts of inventing something new, in fact, the processes supporting innovation are quite complex and change as an idea is seeded until it reaches the market as a product or service. In particular, the following research topics are relevant:

- Global Brain. The ultimate instantiation of the open innovation model is captured with the imagery of the global brain, where it is necessary to research technology and processes that enable manufacturing enterprises to engage with the collective intelligence of all individuals within the global reach of the internet and across cultural barriers.

- Learn to Innovate. The ability to create has long been regarded as an innate attribute of an individual, but it is a cognitive ability and consequently it is feasible for individuals to improve. However, the development of innovation capability also applies to organizations as they distil best practice and mature their processes. It is necessary to research new approaches to competence 
development that target the associated competences in ever smaller time-tocompetence time slots.

- Go Green. Rather than regarding sustainability as an impending hurdle with legal and regularity entanglements, enterprises can embrace it as an opportunity for change and become first movers into new markets. The challenge is to research new frameworks that address the challenges of manufacturing enterprises to adopt sustainability as a means to become competitive.

- Living Labs. The potential of involving the consumer in the innovation process from its inception holds enticing promises, from achieving higher success in innovation outcomes to creating a market ready to consumer the resulting invention. The living labs movement is relatively new, requiring further research into facilitating the implementing and transferring knowledge concerning living labs paradigm to manufacturing enterprises.

- Risk Management. The complexity of reality with its multi-faceted social dependencies makes randomness difficult to predict with a model, thus it is necessary to research new ways of coping and attenuating risks of low probability but with high impact.

\section{References}

1. Wang, C.L., Ahmed, P.K.: Organisational Learning: A Critical Review. The Learning Organization 10, 8-17 (2003)

2. EIS: European Innovation Scoreboard 2008. Comparative Analysis of Innovation Performance. European Commission - Enterprise and Industry, Luxemburg (2009)

3. Parvan, S.: Quality in the Focus of Innovation. Eurostat. Statistics in Focus, 1-8 (2009)

4. Bauer, R.: Kein Bedarf für Plastikräder. Freitag, 43 (2005)

5. INA: Innovation Network Austria Study (2005)

6. Bayless, D.: Innovation, Clockspeed and the Red Queen Effect, http://www . evergreenip.com/presentations/redqueen/redqueen.html

7. Camarinha-Matos, L.M.: Advances in Collaborative Networked Organisations. In: Azevedo, AmericoInnovation in Manufacturing Networks, pp. 3-16. Springer, New York (2008)

8. Adams, W.M.: The Future of Sustainability: Re-thinking Environment and Development in the Twenty-first Cenury, http://cmsdata.iucn.org/downloads/iucn_ future_of_sustanability.pdf

9. Jansson, K., Thoben, K.-D.: The Extended Products Paradigm, An Introduction. In: Arai, E., Kimura, F., Goossenaerts, J., Shirase, K. (eds.) Knowledge and Skill Chains in Engineering and Manufacturing. Information Infrastructure in the Era of Global Communications, pp. 39-47. Springer, New York (2005)

10. Chesbrough, H.W.: Open Innovation. Harvard Business School Press, Boston (2003)

11. Schumacher, J., Niitamo, V.-P.: European Living Labs. A New Approach for Human Centric Regional Innovation. wvb (2008)

12. Baldwin, J., Hanel, P.: Innovation and Knowledge Creation in an Open Economy. Cambridge University Press, Cambridge (2003)

13. Klünder, P.: Planbarer Brückenschlag. Design Report (2006)

14. Akin: An Exploration of the Design Process. Design Methods and Theories (1979)

15. Bauer, B.: Design und Methoden. Design Report (2006) 
16. Gebhard, A.: Rapid Prototyping: Werkzeuge für die schnelle Produktentwicklung. Hanser Fachbuchverlag, Munich (2000)

17. Bessant, J., Stamm, B.v: Twelve Search Strategies that Colud Save your Organisation. Executive Briefing Advanced Institute of Management Research, London (2007)

18. Leifer, R.: Radical Innovation - How Mature Companies can Outsmart Upstarts. Harvard Business School Press, Boston (2000)

19. Hansen, P.K., Mabogunje, A., Moeller Haase, L.: Get a Grip on Sense Making and Exploration. In: Proceedings of the IEEM 2009, Hong Kong (2009)

20. O'Reilly, T.: What Is Web 2.0. Design Patterns and Business Models for the Next Generation of Software, http: / /www. oreillynet.com/pub/a/oreilly/tim/ news / $2005 / 09 / 30 /$ what-is-web-20.html

21. Sigala, M.: Integrating web 2.0 in e-learning environments: A socio-technical approach. International Journal of Knowledge and Learning 3, 628-648 (2007)

22. McAfee, A.P.: Enterprise 2.0: The dawn of emergent collaboration. MIT Sloan Management Review 47, 21-28 (2006)

23. Angehrn, A.A., Maxwell, A., Sereno, B.: Enhancing social interaction in competence development networks: A conceptual framework. International Journal of Learning Technology 3, 424-442 (2008)

24. Angehrn, A.A., Maxwell, A.: TENTube: A video-based connection tool supporting competence development. International Journal of Emerging Technologies in Learning 3, 29-37 (2008)

25. Maslow, A.H.: Motivation and Personality. Harper \& Row, New York (1987)

26. Kerzner, H.: Project Management - A Systems Approach to Planning, Scheduling and Controlling. John Wiley \& Sons, New Jersey (2009)

27. Kahn, K.B.: New Product Forecasting - An Applied Approach, New York (2006)

28. Brussee, W.: Statistics for SixSigma made Easy, New York (2004)

29. Hitt, M.A., Ireland, R.D., Hoskisson, R.E.: Strategic Management - Concept and Cases: Competitiveness and Globalization, Marson (2007)

30. Exner, K.: Controlling in der New Economy - Herausforderungen, Aufgaben, Instrumente, Vienna (2002)

31. Lasher, D.R., Ives, B., Jarvenpaa, S.L.: USAA-IBM Partnerships in Information Technology: Managing the Image Project. MIS-Quarterly 15, 551-565 (1991)

32. Eriksson, M., Niitamo, V.-P., Kulkki, S., Hribernik, K.A.: Living Labs as a MultiContextual R\&D Methodology. In: The 12th International Conference on Concurrent Enterprising: Innovative Products and Services through Collaborative Networks, ICE 2006 (2006)

33. Folstad, A.: Living Labs for Innovation and Development of Information and Communication Technology: A Literature Review. The Electronic Journal for Virtual Organizations and Networks, 99-131 (2008) 